\title{
Synthesis, magnetic and spectral studies on polystyrene-anchored coordination complexes of bi-, tri-, tetra- and hexavalent metal ions with unsymmetrical dibasic tetradentate ONNO donor Schiff base derived from 3-formylsalicylic acid, ethylenediamine and 2-benzoylacetanilide
}

\author{
DINESH KUMAR ${ }^{1}$, ARUN SYAMAL $^{1}$, JAIPAL $^{2}$ and LALIT KUMAR SHARMA ${ }^{3, *}$ \\ ${ }^{1}$ Department of Chemistry, National Institute of Technology, Kurukshetra 136119 \\ ${ }^{2}$ Department of Chemistry, Haryana College of Technology and Management (HCTM), Kaithal 136027 \\ ${ }^{3}$ Applied Science and Humanities Department, Advanced Institute of Technology, Aurangabad, Palwal 121105 \\ e-mail: lalitkkr1976@sify.com
}

MS received 24 August 2007; revised 30 August 2008

\begin{abstract}
Polystyrene-anchored $\mathrm{Cu}(\mathrm{II}), \mathrm{Zn}(\mathrm{II}), \mathrm{Cd}(\mathrm{II}), \mathrm{Ni}(\mathrm{II}), \mathrm{Mn}(\mathrm{II}), \mathrm{MoO}_{2}$ (II), $\mathrm{UO}_{2}(\mathrm{II}), \mathrm{Fe}(\mathrm{III})$ and $\mathrm{Zr}(\mathrm{IV})$, complexes of the unsymmetrical dibasic tetradentate ONNO donor Schiff base derived from the condensation of chloromethylated polystyrene, 3-formylsalicylic acid, ethylenediamine and 2-benzoylacetanilide $\left(\mathrm{PS}-\mathrm{LH}_{2}\right)$ has been synthesized. The polystyrene anchored complexes have the formulae: PS$\mathrm{LM}$ (where $\mathrm{M}=\mathrm{Cu}, \mathrm{Zn}, \mathrm{Cd}, \mathrm{Ni}, \mathrm{MoO}_{2}, \mathrm{UO}_{2}$ ), PS-LFeCl-DMF, PS-LMn·2DMF and PS-LZr $(\mathrm{OH})_{2} \cdot \mathrm{DMF}$. The polystyrene-anchored coordination compounds have been characterized by elemental analysis, IR, reflectance, ESR and magnetic susceptibility measurements. The per cent reaction conversion of polystyrene anchored Schiff base to polystyrene supported coordination compounds lies between 28.98 and 85.9. The coordinated dimethylformamide is completely lost on heating the complexes. The shifts of the $v(\mathrm{C}=\mathrm{N})$ (azomethine) and $v(\mathrm{C}-\mathrm{O})$ (phenolic) stretches have been monitored in order to find out the donor sites of the ligands. The $\mathrm{Cu}$ (II) complex is paramagnetic with square planar structure; the $\mathrm{Ni}$ (II) complex is diamagnetic with square planar structure; the $\mathrm{Zn}(\mathrm{II})$ and $\mathrm{Cd}(\mathrm{II})$ complexes are diamagnetic and have tetrahedral structure; the $\mathrm{Mn}(\mathrm{II})$ and $\mathrm{Fe}(\mathrm{III})$ complexes are paramagnetic and have octahedral structure; the $\mathrm{MoO}_{2}$ (II) and $\mathrm{UO}_{2}(\mathrm{II})$ complexes are diamagnetic and have octahedral structure and the $\mathrm{Zr}(\mathrm{IV}) \mathrm{com}-$ plexes are diamagnetic and have pentagonal bipyramidal structure.
\end{abstract}

Keywords. Polystyrene-anchored ligands; polystyrene-anchored complexes; tetradentate; IR; reflectance; ESSR and magnetic susceptibility measurements.

\section{Introduction}

In recent years there has been considerable interest in the synthesis and use of functionalized polymers having chelating abilities due to their practical convenience, operational flexibility and formation of coordination with high metal to polymer bond energies. ${ }^{1-4}$ Although a large number of bidentate ${ }^{5-7}$ and tridentate ${ }^{8-21}$ ligands have been anchored to polymer matrix, only a few multidentate ligands like triethylenetetramine, ${ }^{22}$ tetraethylenepentamine, ${ }^{23} 1,4,8,11$ tetraazocyclotetradecane, ${ }^{24}$ phthalocyanine, ${ }^{24}$ porphyrine, ${ }^{25}$ dithio-carbamate, ${ }^{26}$ imidazole, ${ }^{27}$ crown

\footnotetext{
*For correspondence
}

ethers, ${ }^{28}$ tetrathiol, ${ }^{29} \mathrm{~N}$-phenacyl-4,4-bipyridinium bromide, ${ }^{30} 2,2^{\prime}$-[diimino-1,2-ethanediylbis(1,2-ethanediylnitrilo-methylidyne) $]$ diphenol, ${ }^{19}{ }^{9} N, N^{\prime}$-ethylenebis(7-salicylialdimine-5-sodium-sulphonate) $)^{31}, N, N^{\prime}$ iminobis(ethylenesalicylideneimine), ${ }^{32} N, N^{\prime}$-iminobis (propylenesalicylideneimine) $^{32}, o$-phenylenebis(Salicylialdimine), ${ }^{33} \quad N, N^{\prime}$-diethyl-enetriaminebis(salicylialdimine) ${ }^{34} \quad N, N^{\prime}$-ethylenebis(5-vinylsalicylideneimine), ${ }^{35} \mathrm{~N}, \mathrm{~N}^{\prime}$-ethylenebis(salicylideneimine), ${ }^{36} \mathrm{~N}$ salicylideneimine- $N^{\prime}$ (3-carboxysalicylidene-imine) ethane $^{37}$, etc. have been anchored to polymer matrix. Since metal chelates of anilide ligands ${ }^{38}$ are receiving increasing attention in view of their biological significance, ${ }^{39}$ transition metal complexes have been prepared using $N, N^{\prime}$-bis(acetoacetanilide)ethylenediamine $^{40}$ and $N, N^{\prime}$-bis(acetoacetanilide)-1,3-diamino- 

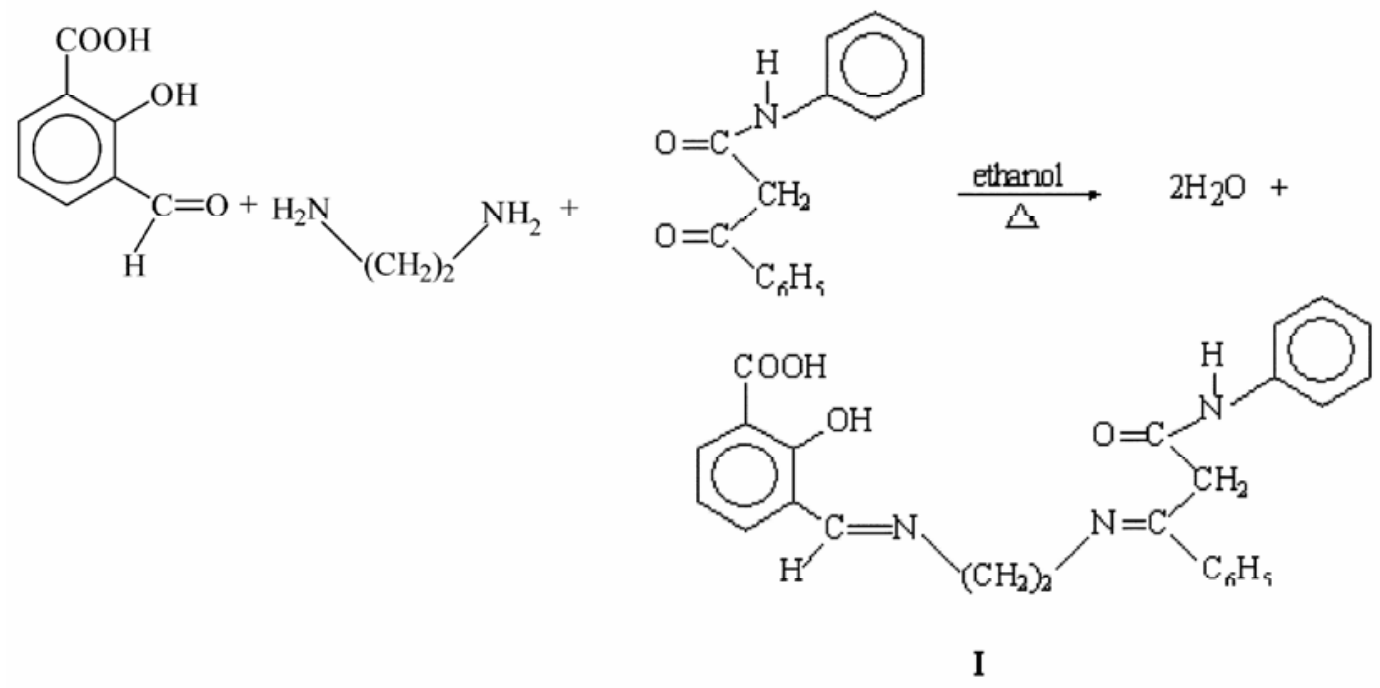

Scheme 1.

propane. ${ }^{41}$ The above non-anchored Schiff base have been used to synthesize and characterize the polymer-anchored $\mathrm{Cu}$ (II) and $\mathrm{Zn}$ (II) complexes. The non-anchored Schiff base (I) behaves as strong field quadridentate ligand.

\section{Experimentals}

\subsection{Materials}

2-Benzoylacetanilide [Aldrich Chemie], ethylenediamine [Sarabhai M Chemicals Co], ammonium molybdate tetrahydrate (Glaxo); copper(II) acetate dihydrate, cadmium(II) acetate dihydrate, iron(III) chloride(anhydrous), dioxo-uranium(VI) acetate tetrahydrate, zinc(II) acetate dihydrate, hexadecaaquaoctahydroxotetrazirconium(IV) chloride(BDH); nickel (II) acetate tetrahydrate (Fluka AG (Switzerland)); manganese(II) acetate tetrahydrate (Sarabhai M Chemicals Co.) were used for the syntheses. Chloromethylated polystyrene [Fluka AG (Switzerland)], DMF, DMSO, $\mathrm{CH}_{3} \mathrm{COOC}_{2} \mathrm{H}_{5}\left(\mathrm{C}_{2} \mathrm{H}_{5}\right)_{3} \mathrm{~N}$ etc. (Glaxo) were used for the syntheses. 3-Formylsalicylic acid, bis(acetylacetonato)dioxomolybdenum(VI) and hexadecaaquaocta-hydroxotetrazirconium(IV) acetate were synthesized according to the literature procedures. ${ }^{42-44}$

\subsection{Analysis and physical measurements}

The metal contents in the polystyrene supported coordination compounds were analysed as per the reported methods. ${ }^{45}$ The coordinated DMF was determined by heating the complexes at a temperature (in vacuo) given in parenthesis: $\mathrm{Ni}$ (II), $\mathrm{Co}$ (II), $\mathrm{Fe}(\mathrm{III})$ complexes $\left(110^{\circ} \mathrm{C}\right), \mathrm{Cu}$ (II) complex $\left(105^{\circ} \mathrm{C}\right)$, $\mathrm{Zn}(\mathrm{II})$ complex $\left(160^{\circ} \mathrm{C}\right), \mathrm{Cd}(\mathrm{II})$ complex $\left(170^{\circ} \mathrm{C}\right)$ and $\mathrm{U}(\mathrm{VI})$ and $\mathrm{Mo}(\mathrm{VI})$ complexes $\left(180^{\circ} \mathrm{C}\right)$. The IR spectra were recorded in $\mathrm{KBr}$ pellets on a Nicolet 5DX FTIR Spectrophotometer calibrated with polystyrene. The magnetic susceptibilities were measured at room temperature by the Gouy method using $\mathrm{Hg}\left[\mathrm{Co}(\mathrm{NCS})_{4}\right]$ as the calibrant. ${ }^{46}$ The paramagnetic susceptibilities were corrected for the diamagnetism of ligand and metal atoms. ${ }^{47}$ Reflectance spectra were recorded on a Beckman DU spectrophotometer attached with a reflectance arrangement. ESR spectra were recorded at liquid nitrogen temperature in polycrystalline solids on a Varian V4502 X-band ESR Spectrophotometer with $100 \mathrm{KHz}$ modulation using diphenylpicrylhydrazide as a $g$-marker and monitoring the frequency with a frequency meter.

\subsection{Synthesis of Schiff base}

An ethanolic solution $(20 \mathrm{ml})$ of 3-formylsalicylic acid $(1.66 \mathrm{~g}, 10 \mathrm{mmol})$ was mixed with an ethanolic solution of 2-benzoylacetanilide (10 mmol) and the mixture was kept in an ice bath. To this, an ethanolic solution of ethylenediamine was added drop-wise with constant stirring. The yellow coloured precipitates obtained were suction filtered, washed with ethanol and petroleum ether. The formation of unsymmetrical Schiff base with $75 \%$ after recrystal- 
lized from $\mathrm{CH}_{3} \mathrm{COOC}_{2} \mathrm{H}_{5}$ and dried in vacuo. Yield: $75 \%$. MP $\mathrm{LH}_{2}=235^{\circ} \mathrm{C}$, Found $\mathrm{N} \%=11.30$ against calcd. $\mathrm{N} \%=11.50$.

\subsection{Synthesis of polystyrene-anchored Schiff base $\mathrm{PS}-\mathrm{LH}_{2}$}

PS-Cl $(1.0 \mathrm{~g})$ was allowed to swell in DMF $(30 \mathrm{ml})$ for $45 \mathrm{~min}$. To this suspension, a DMF solution $(50 \mathrm{ml})$ of Schiff base $(3.51 \mathrm{mmol})$ was added. Ethyl acetate $(100 \mathrm{ml})$ and triethylamine $(5 \mathrm{ml})$ were added, and mixture was heated under reflux for $8 \mathrm{~h}$, while stirring magnetically. The colour of $\mathrm{PS}-\mathrm{Cl}$ changed from white to yellow. The mixture was cooled to room temperature, suction filtered, washed several times with DMF, ethyl acetate, ethanol, methanol and acetone. It was then dried in vacuo.

2.5 General method for the synthesis of Cu(II), $\mathrm{Zn}(\mathrm{II}), \mathrm{Cd}(\mathrm{II}), \mathrm{Mn}(\mathrm{II}), \mathrm{UO}_{2}(\mathrm{II})$ and $\mathrm{Ni}(\mathrm{II})$ complexes

PS- $\mathrm{LH}_{2}(0.5 \mathrm{~g})$ was suspended in DMF $(20 \mathrm{ml})$ for $1 \mathrm{~h}$. A DMF solution $(25-40 \mathrm{ml})$ of the appropriate metal salt/metal complex $(1.17 \mathrm{mmol})$ was added to the above suspensions. The mixture was heated under reflux for $8 \mathrm{~h}$, while stirring magnetically. The mixture was cooled to room temperature and the coloured products obtained were suction filtered, washed with DMF, ethanol, methanol and acetone. The compounds were dried in vacuo.

2.5a Synthesis of PS-FeCl.DMF: PS- $\mathrm{LH}_{2}(0.5 \mathrm{~g})$ was suspended in DMF (20 ml) for $1 \mathrm{~h}$. A DMF solution $(30 \mathrm{ml})$ of $\mathrm{FeCl}_{3}$ (anhydrous) $(0.19 \mathrm{~g}$, $1.17 \mathrm{mmol}$ ) was added to the above suspension. The mixture was heated under reflux for $8 \mathrm{~h}$, while stirring magnetically and then cooled to room temperature. The brown coloured products obtained were suction filtered, washed with DMF, ethanol, methanol and petroleum ether and dried in vacuo.

$2.5 \mathrm{~b}$ Synthesis of $\mathrm{PS}-\mathrm{LZr}(\mathrm{OH})_{2} \cdot \mathrm{DMF}$ : $\mathrm{PS}-\mathrm{LH}_{2}$ $(0.5 \mathrm{~g})$ was suspended in DMF $(20 \mathrm{ml})$ for $1 \mathrm{~h}$. A freshly prepared DMF solution $(50 \mathrm{ml})$ of zirconium(IV) acetate $(2.34 \mathrm{mmol})$ was added to the above suspension. The mixture was heated under reflux for $8 \mathrm{~h}$, while stirring magnetically. The cream coloured products obtained were suction filtered, washed with DMF, ethanol methanol and acetone and dried in vacuo.
$2.5 \mathrm{c}$ Synthesis of $\mathrm{PS}-\mathrm{LMoO}_{2}$ : $\mathrm{PS}-\mathrm{LH}_{2}(0.5 \mathrm{~g})$ was suspended in DMF $(20 \mathrm{ml})$ for $1 \mathrm{~h}$. A DMF solution $(25 \mathrm{ml}$ of bis(acetylacetonato)dioxomolybdenum (VI) $(0.383 \mathrm{~g}, 1.17 \mathrm{mmol})$ was added to the above suspension. The mixture was refluxed for $8 \mathrm{~h}$, while stirring magnetically. The mixture was cooled to room temperature and the yellow coloured products obtained were suction filtered, washed with DMF, ethanol, methanol and acetone and then dried in vacuo.

\section{Results and discussion}

The reaction of chloromethylated polystyrene with $\mathrm{LH}_{2}$ in $1:>3$ molar ratio in DMF in presence of ethyl acetate (EA) and triethylamine (TEA) results in the formation of polystyrene-anchored Schiff base, $\mathrm{PS}-\mathrm{LH}_{2}$. PS-Cl is white, while PS- $\mathrm{LH}_{2}$ is yellow. As the reaction between PS-Cl and $\mathrm{LH}_{2}$ occurs, the white colour of the PS-Cl changes to yellow. This colour remains unchanged even after the prolonged washings with DMF, ethyl acetate, ethanol and petroleum ether. In the synthesis of PS- $\mathrm{LH}_{2}$ the per cent reaction conversion was found to be 100 and there was no chlorine present in the polystyreneanchored Schiff base. This was possible only since we repeated $\mathrm{PS}-\mathrm{Cl}$ and $\mathrm{LH}_{2}$ in ratio, $1: 3$. If the ratio was $1:<3$, the corresponding polystyrene-anchored Schiff base always contained some unreacted $-\mathrm{CH}_{2} \mathrm{Cl}$ group. For the synthesis of polystyrene supported complexes, PS-Cl (containing $1.17 \mathrm{mmol}$ of $\mathrm{Cl}$ per $\mathrm{g}$ of resin and $2 \%$ crosslinked with divinylbenzene) was selected since a higher crosslinking than $2 \%$ hinders the reactivity and metal binding power of the polystyrene supported Schiff base. The reaction of PS- $\mathrm{LH}_{2}$ and appropriate metal salts in $2: 1$ molar ratio in DMF gives polystyrene supported coordination compounds of the types: PS-LM [where $\mathrm{M}=\mathrm{Cu}(\mathrm{II}), \mathrm{Zn}(\mathrm{II}), \mathrm{Cd}(\mathrm{II}), \mathrm{Ni}(\mathrm{II}), \mathrm{UO}_{2}(\mathrm{II})$ ], PS-LMoO ${ }_{2}$. DMF, PS-LFeCl-DMF and PS-LZr $(\mathrm{OH})_{2}$.DMF. The formation of coordination compounds may be represented by taking the representative case of $\mathrm{PS}-\mathrm{LH}_{2}$ by the following equations:

$$
\begin{gathered}
\mathrm{PS}-\mathrm{LH}_{2}+\mathrm{M}\left(\mathrm{CH}_{3} \mathrm{COO}\right)_{2} \\
\mathrm{PS}-\mathrm{LM}+2 \mathrm{CH}_{3} \mathrm{COOH} \\
\text { reflux } \\
{\left[\mathrm{M}=\mathrm{Cu}(\mathrm{II}), \mathrm{Ni}(\mathrm{II}), \mathrm{Zn}(\mathrm{II}), \mathrm{Cd}(\mathrm{II}) \text { and } \mathrm{UO}_{2}(\mathrm{II})\right]} \\
\mathrm{PS}-\mathrm{LH}_{2}+\mathrm{Mn}\left(\mathrm{CH}_{3} \mathrm{COO}\right)_{2} \\
\mathrm{PMF} \\
\mathrm{PS}-\mathrm{LMn} \cdot 2 \mathrm{DMF}+2 \mathrm{CH}_{3} \mathrm{COOH}
\end{gathered}
$$


Table 1. Colour, analytical and other characterization data of polystyrene-anchored compounds ${ }^{\mathrm{a}}$.

\begin{tabular}{|c|c|c|c|c|c|}
\hline \multirow[b]{2}{*}{ Compounds } & \multirow[b]{2}{*}{ Colour } & \multicolumn{2}{|c|}{ Found (calcd) (\%) } & \multirow{2}{*}{$\begin{array}{l}\text { Per cent reaction } \\
\text { conversion }^{b}\end{array}$} & \multirow{2}{*}{$\begin{array}{l}\text { Metal binding capacity } \\
(\mathrm{mmol} / \mathrm{g} \text { of resin })\end{array}$} \\
\hline & & M & DMF & & \\
\hline $\mathrm{PS}-\mathrm{LCu}$ & Yellowish green & $3 \cdot 8(4 \cdot 86)$ & - & $78 \cdot 2$ & 0.59 \\
\hline PS-LNi & Pale yellow & $3 \cdot 0(4 \cdot 50)$ & - & $66 \cdot 66$ & 0.51 \\
\hline PS-LZn & Cream & $3.0(4.99)$ & - & $60 \cdot 12$ & $0 \cdot 46$ \\
\hline PS-LCd & Cream & $2 \cdot 4(8 \cdot 28)$ & - & $28 \cdot 98$ & $0 \cdot 21$ \\
\hline $\mathrm{PS}-\mathrm{LMoO}_{2}$ & Yellow & $3 \cdot 3(6 \cdot 99)$ & - & $47 \cdot 21$ & $0 \cdot 34$ \\
\hline PS-LUO 2 & Yellow & $11 \cdot 3(15 \cdot 71)$ & - & $71 \cdot 9$ & $0 \cdot 47$ \\
\hline PS-LMn·2DMF & Dark brown & $2 \cdot 4(3.80)$ & $6 \cdot 4(10 \cdot 19)$ & $63 \cdot 16$ & 0.44 \\
\hline PS-LFeCl·DMF & Brown & $3.4(3.96)$ & $3 \cdot 9(5 \cdot 23)$ & $85 \cdot 9$ & $0 \cdot 61$ \\
\hline $\mathrm{PS}-\mathrm{LZr}(\mathrm{OH})_{2} \cdot \mathrm{DMF}$ & Cream & $3 \cdot 6(6 \cdot 32)$ & $2 \cdot 9(5 \cdot 47)$ & $56 \cdot 9$ & $0 \cdot 39$ \\
\hline
\end{tabular}

${ }^{\mathrm{a}}$ Abbreviations: PS-LH $=\mathrm{I}, \mathrm{DMF}=$ dimethylformamide. ${ }^{\mathrm{b}}$ Per cent reaction conversion $(\mathrm{p})=($ observed metal ion percentage $\times 100) /($ calculated metal ion per centage on the basis $100 \%$ reaction conversion of polystyrene-anchored ligand to polystyrene-anchored complex). ${ }^{\mathrm{c}}$ Metal binding capacity $=[\mathrm{M} \%$ (observed $\left.) \times 10\right] /($ atomic weight of metal)

$$
\begin{aligned}
\text { PS- } \mathrm{LH}_{2} & +\mathrm{FeCl}_{3} \underset{\text { reflux }}{\mathrm{DMF}} \mathrm{PS}-\mathrm{LFeCl} \cdot \mathrm{DMF}+2 \mathrm{HCl} \\
\mathrm{PS}-\mathrm{LH}_{2} & +\mathrm{MoO}_{2}(\mathrm{acac})_{2} \underset{\text { reflux }}{\mathrm{DS}-\mathrm{LMoO}_{2}+2 \mathrm{acacH}} \\
4 \mathrm{PS}-\mathrm{LH}_{2} & +\left[\mathrm{Zr}_{4}(\mathrm{OH})_{8}\left(\mathrm{H}_{2} \mathrm{O}\right)_{16}\right]\left(\mathrm{CH}_{3} \mathrm{COO}\right)_{8} \frac{\mathrm{DMF}}{\mathrm{reflux}} \\
& 4 \mathrm{PS}-\mathrm{LZr}(\mathrm{OH})_{2} \cdot \mathrm{DMF}+8 \mathrm{CH}_{3} \mathrm{COOH} \\
& +16 \mathrm{H}_{2} \mathrm{O} .
\end{aligned}
$$

In the synthesis of polystyrene-anchored complexes, the Schiff base: metal ratio was maintained as $1: 2$ and this leads to the per cent reaction conversion between 28.98-85.9 (table 1). There is no apparent correlation between the size of the metal ions and the per cent reaction conversion. The metal binding capacity of the resins is in the range: $0 \cdot 21-0.61 \mathrm{mmol}$ per $g$ of resin (table 1). The colour of the polystyrene-anchored Schiff base is yellow, while that of polystyrene-anchored complexes are pale yellow, yellow, cream, brown, dark brown. The colours of the metal bound polymers remains unchanged even after repeated washings with DMF, ethanol, methanol and acetone.

3-Formylsalicylic acid exhibits a broad band at $3320 \mathrm{~cm}^{-1}$, a strong band at $1660 \mathrm{~cm}^{-1}$ and a medium intense band at $1540 \mathrm{~cm}^{-1}$ due to $v(\mathrm{OH})$ (intramolecular H-bonding), ${ }^{48} v(\mathrm{C}=\mathrm{O})$ (carboxylic/ aldehyde) and $v(\mathrm{C}-\mathrm{O})$ (phenolic) stretch respectively. These bands occur at the same energy in $\mathrm{LH}_{2}$ along with the appearance of a strong band between $1625 \mathrm{~cm}^{-1}$. The latter may be assigned to $v(\mathrm{C}=\mathrm{N})$ (azomethine) stretch. ${ }^{16}$ In PS- $\mathrm{LH}_{2}$, the band at $1660 \mathrm{~cm}^{-1}$ disappears and a new strong band at $1730 \mathrm{~cm}^{-1}$ appears, indicating the formation of ester linkage between PS-Cl and 3-formylsalicylic acid moiety. ${ }^{17-19}$ The polystyrene-anchored coordination compounds, except the corresponding $\mathrm{Zr}$ (IV) complex, do not exhibit this band. The disappearance of this band upon complexation indicates the breakdown of H-bonding followed by deprotonation of phenolic $\mathrm{OH}$ group and the subsequent involvement of phenolic oxygen atom towards coordination. ${ }^{16}$ The polystyrene-anchored zirconium(IV) complex exhibits above band at $3400 \mathrm{~cm}^{-1}$ indicating the presence of coordinated $\mathrm{OH}$ groups. PS- $\mathrm{LH}_{2}$ occur in keto form as evident by the presence of a band between $1675 \mathrm{~cm}^{-1}$. This band disappears in the polystyrene-anchored coordination compounds and a new band between 1225 and $1260 \mathrm{~cm}^{-1}$ due to $v(\mathrm{C}-\mathrm{O})$ (enolic) stretch appears. ${ }^{49}$ The negative shift of $v(\mathrm{C}=\mathrm{N}) \operatorname{stretch}^{50}$ by $10-25 \mathrm{~cm}^{-1}$ and the positive shift ${ }^{51}$ of $v(\mathrm{C}-\mathrm{O})$ (phenolic) stretch by $\leq 10 \mathrm{~cm}^{-1}$ upon complexation, indicates the dibasic tetradentate ONNO donor nature of PS- $\mathrm{LH}_{2}$. DMF exhibits a band at $1680 \mathrm{~cm}^{-1}$ due to the $v(\mathrm{C}=\mathrm{O})$ stretch which shifts to lower energy by $10-30 \mathrm{~cm}^{-1}$ in the spectra of metal bound polymers indicating oxygen coordination of DMF. ${ }^{52}$ The polystyrene-anchored compounds, PS- $\mathrm{LMoO}_{2}$ exhibits two bands at $950 \mathrm{~cm}^{-1}$ and $910 \mathrm{~cm}^{-1}$ due to $v_{\mathrm{sy}}(\mathrm{O}=\mathrm{M}=\mathrm{O})$ and $v_{\text {asy }}(\mathrm{O}=\mathrm{M}=\mathrm{O})$ stretches respectively. ${ }^{16-18,53}$ These bands are in the usual ranges $\left(892-964 \mathrm{~cm}^{-1}\right.$ and $\left.840-925 \mathrm{~cm}^{-1}\right)$ assigned for $v_{\mathrm{sy}}(\mathrm{O}=\mathrm{Mo}=\mathrm{O})$ and $v_{\text {asy }}(\mathrm{O}=\mathrm{Mo}=\mathrm{O})$ stretches respectively, reported for the majority of dioxomolybdenum(VI) complexes. ${ }^{16-18,53}$ The data indi- 


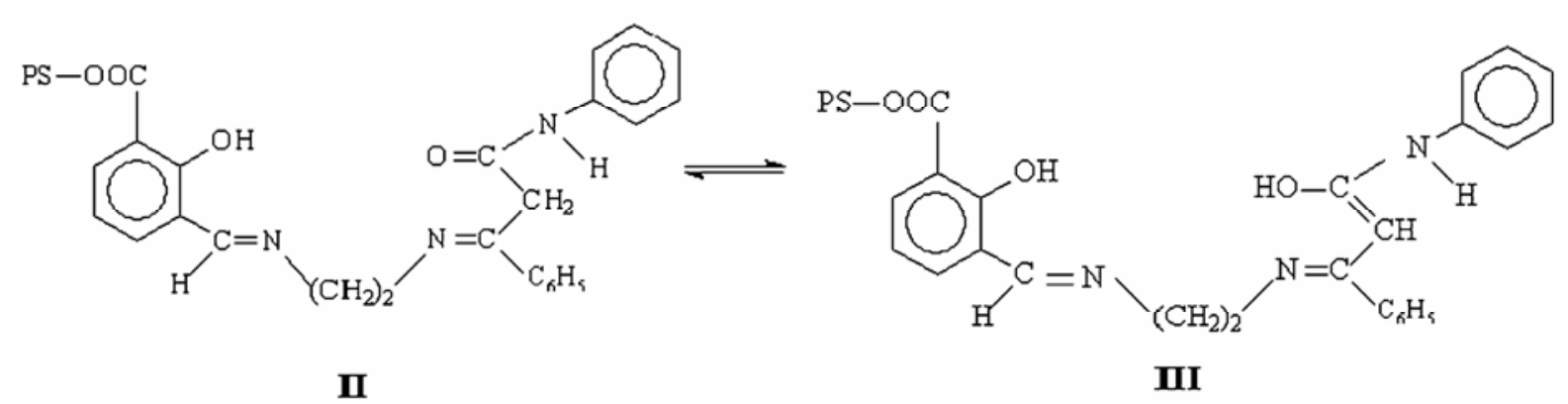

Scheme 2.

cate the presence of $c i s-\mathrm{MoO}_{2}$ structure, since a compound with a trans $-\mathrm{MoO}_{2}$ moiety is expected to show only the $v_{\text {asy }}(\mathrm{O}=\mathrm{Mo}=\mathrm{O})$ stretch ${ }^{53}$ The data rule out the presence of oligomeric structure $\cdots \mathrm{Mo}=$ $\mathrm{O} \cdots \mathrm{Mo}=\mathrm{O} \cdots$ in which $v(\mathrm{Mo}=\mathrm{O})$ is expected to occur at $<850 \mathrm{~cm}^{-1} \cdot{ }^{54} \mathrm{PS}-\mathrm{LUO}_{2}$ exhibits a strong band at $910 \mathrm{~cm}^{-1}$ due to the $v_{\text {asy }}(\mathrm{O}=\mathrm{U}=\mathrm{O})$ stretch, which occurs in the reported range $\left(870-950 \mathrm{~cm}^{-1}\right)$ observed for the majority of dioxouranium(VI) compounds. ${ }^{55}$ The observation of only one $v_{\text {asy }}(\mathrm{O}=\mathrm{U}=\mathrm{O})$ band indicates the presence of the trans- $\mathrm{UO}_{2}$ structure since the $v_{\mathrm{sy}}(\mathrm{O}=\mathrm{U}=\mathrm{O})$ is infrared inactive. The force con$\operatorname{stant}\left(f_{\mathrm{U}-\mathrm{O}}\right)$ is $6.88 \mathrm{mdyn} / \AA$ which agrees well with those of other $\mathrm{UO}_{2}$ (II) complexes. The $\mathrm{U}-\mathrm{O}$ bond distance(R) is $1.74 \AA$ which is in the usual range (1.60-1.92 $\AA$ ) observed for the majority of $\mathrm{UO}_{2}$ (II) complexes. ${ }^{55,56}$ The oxobridged iron(III) coordination compounds usually show a band in the region: $820-860 \mathrm{~cm}^{-1}$ due to ${ }_{\mathrm{Fe}}{ }^{\circ}$ Fe bridge. ${ }^{16-18,57}$ No such band in the above region could be observed in PSLFeCl-DMF indicating the non-participation of the phenolic oxygen atom in the bridge formation. The absence of a band in the range: $835-956 \mathrm{~cm}^{-1}$, characteristic of the $v(\mathrm{Zr}=0)$ stretch $^{58}$ in polystyreneanchored zirconium(IV) coordination compound suggests the formulation of compounds as PS$\mathrm{LZr}(\mathrm{OH})_{2}$. DMF and not as PS-LZrO $\left(\mathrm{H}_{2} \mathrm{O}\right) \cdot \mathrm{DMF}$. The appearance of a new band at around $1115 \mathrm{~cm}^{-1}$ due to the $\delta(\mathrm{Zr}-\mathrm{OH})$ mode also supports the suggested formulation of polystyrene-anchored zirconium(IV) coordination compound. ${ }^{59}$ The room temperature magnetic susceptibilities and magnetic moments of the polystyrene-anchored coordination compounds are presented in table 2. PS-LCu exhibits magnetic moment $1.98 \mathrm{BM}$. This value is within the range: $1.75-2.2 \mathrm{BM}$ reported for $\mathrm{Cu}$ (II) coordination compounds. ${ }^{60}$ PS-LFeCl-DMF exhibits magnetic moment 5.99 BM. This value is within the range of 5.8-6.02 $\mathrm{BM}$ expected for high spin magnetically dilute $\mathrm{Fe}(\mathrm{III})$ complexes. ${ }^{61}$ PS-LMn-2DMF exhibits magnetic moment $5.90 \mathrm{BM}$. This value is within the range of 5.88-5.92 BM expected for high spin magnetically dilute $\mathrm{Mn}(\mathrm{II})$ complexes. ${ }^{62} \mathrm{PS}-$ LNi is diamagnetic with square planar structure. ${ }^{63}$ The zinc(II), cadmium(II), dioxomolybdenum(VI) and dioxouranium(VI) complexes are diamagnetic as expected. A tetrahedral structure for $\mathrm{Zn}$ (II) and $\mathrm{Cd}(\mathrm{II})$ complexes; a square planar structure for $\mathrm{Cu}(\mathrm{II})$, $\mathrm{Ni}$ (II) and $\mathrm{Co}(\mathrm{II})$ polystyrene-anchored complexes; an octahedral structure for $\mathrm{MoO}_{2}$ (II) and $\mathrm{UO}_{2}$ (II) complexes and a pentagonal bipyramidal structure for $\mathrm{Zr}(\mathrm{IV})$ complex are suggested.

Nujol mull electronic spectra of the polystyrenesupported coordination compounds could not be recorded, as the compounds do not form a good mull and hence, the reflectance spectra of compounds were recorded. The compounds being insoluble in common solvents, the solution electronic spectra also could not be recorded. PS-LCu exhibits an asymmetric broad band at $18,600 \mathrm{~cm}^{-1}$ which is assigned to the envelope of ${ }^{2} B_{1 g} \rightarrow{ }^{2} A_{1 g},{ }^{2} B_{2 g}$ and ${ }^{2} E_{g}$ transition for square planar arrangement of ligand around copper(II) ions. ${ }^{64}$ PS-LNi complex exhibits a weak band at $12,300 \mathrm{~cm}^{-1}\left(v_{1}\right)$ which is assigned to a spin-forbidden ${ }^{1} \mathrm{~A}_{1 \mathrm{~g}} \rightarrow{ }^{3} \mathrm{~A}_{2 \mathrm{~g}}$ transition. ${ }^{65,66} \mathrm{~A}$ strong band at $24,000 \mathrm{~cm}^{-1}\left(v_{3}\right)$ in the present compound is assigned to the ${ }^{1} \mathrm{~A}_{1 \mathrm{~g}} \rightarrow{ }^{1} \mathrm{~B}_{1 \mathrm{~g}}$ transition. ${ }^{65} \mathrm{We}$ were unable to locate the $v_{2}$ band ${ }^{1} \mathrm{~A}_{1 \mathrm{~g}} \rightarrow{ }^{1} \mathrm{~A}_{2 \mathrm{~g}}$ transition at around $20000 \mathrm{~cm}^{-1}$ as it is probably merged underneath the strong $v_{3}$ transition. Hobday et $a l^{67}$ have also reported the presence of a single band at $23,000 \mathrm{~cm}^{-1}$ in the spectra of square planar, Ni(salen) $\mathrm{SnX}_{2}$ (where $\mathrm{X}=\mathrm{Cl}, \mathrm{Br}$ ). PS-LFeCl-DMF exhibits three bands at $12,000 \mathrm{~cm}^{-1}, 22000 \mathrm{~cm}^{-1}$ and $26,800 \mathrm{~cm}^{-1}$ due to the ${ }^{6} \mathrm{~A}_{1 \mathrm{~g}} \rightarrow{ }^{4} \mathrm{~T}_{1 \mathrm{~g}}(\mathrm{G}),{ }^{6} \mathrm{~A}_{1 \mathrm{~g}} \rightarrow{ }^{4} \mathrm{~T}_{2 \mathrm{~g}}(\mathrm{G})$ and ${ }^{6} \mathrm{~A}_{1 \mathrm{~g}} \rightarrow{ }^{4} \mathrm{~A}_{1 \mathrm{~g}}(G)$ transitions, respectively in an 
Table 2. Infrared spectral data $\left(\mathrm{cm}^{-1}\right)$, magnetic susceptibility measurements and magnetic moments of the polystyrene-anchored compounds.

\begin{tabular}{|c|c|c|c|c|c|}
\hline Compounds & $\begin{array}{c}v(\mathrm{C}=\mathrm{N}) \\
\text { (azomethine) }\end{array}$ & $\begin{array}{c}v(\mathrm{C}-\mathrm{O}) \\
\text { (phenolic) }\end{array}$ & $\left(10^{-6} \stackrel{\chi_{\text {dia }}}{\text { cgs units })}\right.$ & $\left(10^{-6} \stackrel{\chi_{\mathrm{M}}^{\mathrm{corr}}}{\mathrm{cgs} \text { units })}\right.$ & $\begin{array}{c}\text { Magnetic moment } \\
\text { BM }[\mathrm{K}]\end{array}$ \\
\hline $\mathrm{LH}_{2}$ & 1625 & 1540 & - & - & - \\
\hline PS- $-\mathrm{LH}_{2}$ & 1625 & 1540 & - & - & - \\
\hline PS-LCu & 1610 & 1555 & -1052 & 1642 & $1.98[298]$ \\
\hline PS-LNi & 1605 & 1545 & - & - & Diamagnetic \\
\hline PS-LZn & 1615 & 1545 & - & - & Diamagnetic \\
\hline PS-LCd & 1600 & 1550 & - & - & Diamagnetic \\
\hline PS-LMoO 2 & 1600 & 1545 & - & - & Diamagnetic \\
\hline PS-LUO 2 & 1605 & 1550 & - & - & Diamagnetic \\
\hline PS-LMn·2DMF & 1610 & 1545 & -1387 & 14484 & $5.90[300]$ \\
\hline PS-LFeCl·DMF & 1600 & 1545 & -1015 & 14970 & $5 \cdot 99[300]$ \\
\hline $\mathrm{PS}-\mathrm{LZr}(\mathrm{OH})_{2} \cdot \mathrm{DMF}$ & 1600 & 1550 & - & - & Diamagnetic \\
\hline
\end{tabular}

${ }^{\mathrm{a}} \mu_{\mathrm{eff}}=2 \cdot 83\left(\chi_{\mathrm{M}}^{\mathrm{corr}} \times T\right)^{1 / 2} \mathrm{BM}$

octahedral symmetry. ${ }^{68}$ PS-LMn.2DMF exhibits three bands at $18,430 \mathrm{~cm}^{-1}, 22,970 \mathrm{~cm}^{-1}$ and $25,210 \mathrm{~cm}^{-1}$ due to the ${ }^{6} \mathrm{~A}_{1 \mathrm{~g}} \rightarrow{ }^{4} \mathrm{~T}_{1 \mathrm{~g}}(\mathrm{G}),{ }^{6} \mathrm{~A}_{1 \mathrm{~g}} \rightarrow{ }^{4} \mathrm{~T}_{2 \mathrm{~g}}(\mathrm{G})$ and ${ }^{6} \mathrm{~A}_{1 \mathrm{~g}} \rightarrow$ ${ }^{4} \mathrm{~A}_{1 \mathrm{~g}}(\mathrm{G})$ transitions, respectively in an octahedral symmetry ${ }^{68}$ It is of interest to note that although both $\mathrm{Mn}(\mathrm{II})$ and $\mathrm{Fe}$ (III) have ${ }^{6} \mathrm{~A}_{1 \mathrm{~g}}$ ground state, all the bands occur in Fe (III) compound at lower energy than those of $\mathrm{Mn}$ (II) compound. This is due to lower value of Racah parameters (B\&C) in Fe(III) compound to those of $\mathrm{Mn}(\mathrm{II})$ compound.

The presence of diamagnetic large polystyrene backbone keeps the, metal centres in the polystyrene-anchored compounds considerably separated which avoids dipolar broadening. As a result, reasonably good ESR spectra were observed in polycrystalline solids in the absence of a host diamagnetic coordination compound diluent. The ESR spectrum of PS-LCu show two $g$-values $\left(g_{\|}=2.18\right.$, and $\left.g_{\perp}=2.05\right)$ indicating the presence of a tetragonal type symmetry about the $\mathrm{Cu}(\mathrm{II})$ ion. ${ }^{69}$ The parameters for PS-LCu are: $A_{\|}=1.68 \times 10^{-2} \mathrm{~cm}^{-1}, A_{\perp}=3.27 \times$ $10^{-3} \mathrm{~cm}^{-1} ; G=3 \cdot 34$. The data indicate that $g_{\perp}<g_{\|}$ and $A_{\perp}<A_{\|}$which are according to expectation. $g_{\|}$is normally $<2.3$ for covalent environments and is $\geq 2.3$ for ionic environments. ${ }^{70}$ PS-LCu exhibits $G$ values(3.34) which identify the ligands as a strong field ligand. The absence of $\Delta M_{\mathrm{s}}=2$ line around 1500 gauss in the EPR spectra of the present $\mathrm{Cu}$ (II) complex rules out the presence of $\mathrm{M}-\mathrm{M}$ interaction. It has been observed that the metal ions are situated on the phenyl rings(or polystyrene) which are 6 to 7 styrene units apart when per cent reaction conver- sion is $<100 \%$. Thus a magnetically dilute environment around the metal ions is maintained since the path way for $\mathrm{M}-\mathrm{M}$ interaction is reduced. But the polystyrene is $2 \%$ cross linked with divinylbenzene, the polymer chain may be overlapped and twisted and this may bring some reactive groups closer leading to $\mathrm{M}-\mathrm{M}$ interaction which was undetectable by the ESR method.

\section{Conclusion}

The mixed Schiff base can be conveniently synthesized under controlled conditions of required molar ratio of carbonyl and amine compounds. The quadridentate ligand is successfully anchored to polystyrene matrix and the polymer bound ligand is capable of acting as a chelating ligand and coordinating with a variety of metal ions. The structures of the metal bound polymers are comparable to those of the metal complexes of non-anchored ligand.

\section{Acknowledgement}

The authors are grateful to the Director, National Institute of Technology, Kurukshetra for financial assistance to carry out this work.

\section{References}

1. Kumar D, Gupta P K and Syamal A 2002 Indian J. Chem. A41 2494

2. Syamal A and Singh M M 1994 React. and Funct. Polym. 2427 
3. Boussetta S, Branger C, Margaillan A, Boudenne J L and Coulomb B 2008 React. and Funct. Polym. 68775

4. Kurumura Y and Takato K 1988 J. Chem. Soc. Faraday Trans-I 84841

5. Cazaux I and Caze C 1993 Eur. Polym. J. 291615

6. Syamal A and Singh M M 1994 React. and Funct. Polym. 2427

7. Syamal A and Singh M M 1993 Indian J. Chem. A32 431; Syamal A and Singh M M 1994 Indian J. Chem. A33 58

8. Masuda S, Kobayashi T and Tomida T 1993 Polymer 344562

9. Syamal A, Kumar D, Singh A K, Gupta P K, Jaipal and Sharma L K 2002 Indian J. Chem. A41 1385

10. Kumar D, Syamal A and Singh A K 2004 Asian J. Chem. 16

11. Syamal A and Singh M M 1992 Indian J. Chem. A31 110

12. Syamal A and Singh M M 1993 React. and Funct. Polym. 2145

13. Syamal A, Ahmed S and Bariniazi M A $1983 \mathrm{~J}$. Indian Chem. Soc. 60493

14. Jain V K, Handa A, Sait S S, Shrivastava P and Agarwal Y K 2000 Anal. Chim. Acta 4-29 237

15. Thamizharsi S, Reddy A V R and Balasubramanium S 1998 Eur. Polym. J. 341605

16. Kumar D, Syamal A and Singh A K 2003 Indian J. Chem. A42 280

17. Kumar D, Gupta P K and Syamal A 2002 Indian J. Chem. A41 2494

18. Kumar D, Syamal A and Gupta P K 2003 J. Indian Chem. Soc. 803

19. Syamal A and Singh M M 1992 J. Polym. Mater. 9 105

20. Syamal A and Singh M M 1993 Indian J. Chem. A32 42

21. Syamal A and Singh M M 1993 Indian J. Chem. A32 861

22. Sherai H, Takemoto K and Hojo N 1984 Polym. Commun. 25284

23. Mori H, Shinba H, Fujimura Y and Takegami Y 1989 Nipon Kagaku Kaishi 1855

24. Szcpaniak V and Kuezynsakii K K 1985 React. and Funct. Polym. 3101

25. Pederson C J and Frensdroff H K 1972 Angew. Chem. Int. Edn. Engl. 11 16; Hilal H, Kim C and Schrainer A 1993 J. Mol. Catal. 31157

26. Mathew B and Pillai V N R 1994 Eur. Polym. J. 36 61; Mathur P N, Parashar K and Srivastava S 2000 Indian J. Chem. A39 1327

27. Brown J, Hamerton J and Howlin J B $2000 \mathrm{~J}$. Appl. Polym. Sci. 72201

28. Tomoi T, Abe O, Takasu $\mathrm{N}$ and Kakiuchi $\mathrm{H} 1983$ Makromol. Chim. 183 2431; Hodge P, Khosdel E and Waterhouse J 1984 J. Chem. Soc. Perkin Trans-I 245

29. Nishizawa N, Yokoyama T, Kimura T and Suzuki T M 1986 Polyhedron 5204

30. Druta I, Avram E and Cozan V 1999 Eur. Polym. J. 36221

31. Hassanein M, Abdel-Hay F and El-Esawy T 1994 Eur. Polym. J. 30335
32. Drago R S, Gaul J, Zombeck A and Staub D K 1980 J. Am. Chem. Soc. 1021033

33. Pathak R and Rao G N 1998 J. Mol. Catal. A: Chem. 130215

34. Suzuki T M and Yokoyama T 1983 Polyhedron 2 127; Suzuki T M, Kimura T, Yokoyama T and Matsunaga H 1985 Japan Pat. 615318

35. Akelah A, Abbasi M M and Azad MK H 1986 Indian J. Chem. A25 923

36. Nishikawa H and Yamada S 1964 Bull. Chem. Soc. Japan $\mathbf{3 7} 8$

37. Syamal A, Singh M M and Kumar D 1999 React. and Funct. Polym. 3927

38. Cohn M D and Flavian S 1967 J. Chem. Soc. (B) 317; Sacconi L 1972 J. Am. Chem. Soc. 744503

39. Takeuchi T 1957 J. Antibiot. (Tokyo) 101818

40. Mahapatra B B and Pujari S K 1983 Trans. Met. Chem. 8202

41. Mahapatra B B and Pande D 1984 Trans. Met. Chem. 15117

42. Duff J C and Bills E J 1932 J. Chem. Soc. 1987

43. Chin C J, McDonald J W and Newton W E 1976 Inorg. Chem. 152612

44. Syamal A and Maurya M R 1985 Indian J. Chem. A24 836

45. Lewis J and Wilkins R G 1960 Modern coordination chemistry (New York: Interscience Publishers) p. 412

46. Dutta R L and Syamal A 1993 Elements of magnetochemistry (New Delhi: Affiliated East West Press, (2nd edn) p. 7

47. Dean J A 1985 Lange's hand book of chemistry (Toronto: McGraw Hill) 13th edn

48. Bahad P J, Bhave N S and Aswar A S 2000 J. Indian Chem. Soc. 77363

49. Syamal A and Kale K S 1980 Indian J. Chem. A19 225

50. Teyssi P and Charretta J J 1963 Spectrochim. Acta 19 407

51. Syamal A and. Maurya M R 1985 Indian J. Chem. A24 836

52. Krishnamurthy S S and Soundarajan S 1966 J. Inorg. Nucl. Chem. 291989

53. Syamal A and Maurya M R 1989 Coord. Chem. Rev. 95183

54. Stiefsel E I 1977 Prog. Inorg. Chem. 221

55. Hsieh A T T, Sheahan R M and West B O 1975 Aust. J. Chem. 28 885; Alyea E C, Malek A and Kazi A I 1981 Trans. Met. Chem. 6223

56. McGlynn S P, Smith J H and Neely W C $1961 \mathrm{~J}$. Chem. Phys. 35 105; Jones L H 1958 Spectrochim Acta 10 395; Jones L H 1959 Spectrochim Acta 11 409

57. Howkin D J and Grifith W P 1966 J. Chem. Soc. A 472

58. Spasibenko T P and Goroshchenko Y G 1969 Russ. J. Inorg. Chem. 14758

59. Kharitanov Y Y, Zaitsev L M, Bochkarer G S and Evastafeva O P 1964 Russ. J. Inorg. Chem. 7 1617; Syamal A and Kumar D 1985 Indian J. Chem. A24 62

60. Syamal A 1975 Coord. Chem. Rev. 16309 
61. Cotton F A and Wilkinson G 1985 Advanced inorganic chemistry (New Delhi: Wiley) 3rd edn

62. Syamal A and Gupta B K 1995 Indian J. Chem. A33 495

63. Calvin M and Barkelew C H $1964 \mathrm{~J}$. Am. Chem. Soc. 68 2273; Wills J W and Mellor D P $1947 \mathrm{~J}$. Am. Chem. Soc. 691237

64. Syamal A and Kale K S 1979 Trans. Met. Chem. 4 298

65. Lever A B P 1968 Inorganic electronic spectroscopy (Amsterdam: Elsevier) 2nd edn, and references there in
66. Raman N and Kulandaisamy A 2001 Proc. Indian Acad. Sci. 113 183; Singh N K, Singh D K and Singh J 2001 Indian J. Chem. A40 1064

67. Hobday D and Smith T D 1971 Indian J. Chem. 9590

68. Singh V P and Narang K K 1993 Synth. React. Inorg. Metal-Org. Chem. 23 971; Bhave N S, Bahad P J, Sonparote P M and Aswar A S 2002 J. Indian Chem. Soc. 79342

69. Gersman H R and Neiman R 1962 J. Chem. Phys. 36 3221

70. Kivelson D and Neiman R 1961 J. Chem. Phys. 35 149 